\title{
Novel Approach of PID Control Scheme With UPFC'S for Damping of Oscillations
}

\author{
Sobuj Kumar Ray, Pejush Chandra Sarker, Munshi Sabbir Ahsan, and M. M. Israfil Shahin Seddiqe \\ Member, IACSIT
}

\begin{abstract}
Unified Power Flow Controller (UPFC) is the most versatile FACTS device which has the capabilities of controlling power flow in the transmission lines, improving the transient stability, mitigating system oscillations and providing voltage support by integrating series and shunt compensators. This paper can serve as a compendium of the tremendous amount of new materials being developed in this field. First rotor angle deviation and speed deviation are analysed with and without FACT devices in a Single-Machine Infinite Bus (SMIB) power system, then PID controller is incorporated properly for improving electromechanical oscillation with STATCOM, SSSC and UPFC under step change in turbine mechanical input and faulty condition respectively. The results are compared by using Matlab Simulink.
\end{abstract}

\section{Index Terms-FACT, SSSC, STATCOM, PID.}

\section{INTRODUCTION}

FACTS devices are the most multifarious devices used to control real and reactive power in transmission line for economic, flexible operation in the power system. To control real and reactive power we must be investigated about the voltage magnitude of the transmission, power angle and line impedance. But UPFC allows simultaneous or independent control of all these three parameters, with possible switching from one control scheme to another in real time[1]. Damping of oscillations and transient stability are investigated profoundly throughout the world [2]-[4].

The potential benefits of FACTS equipment are now widely recognized by the power systems engineering and T\&D communities. With respect to FACTS equipment, voltage sourced converter (VSC) technology, which utilizes self-commutated thyristor/transistors such as GTOs, Ws, IGCTs, and IGBTs, has been successfully applied in a number of installations world-wide for Static Synchronous Compensators (STATCOM) [5]-[9]. Unified Power Flow Controllers (UPFC)[10]-[11], Convertible Series Compensators (CSC) [12], back-to-back dc ties (VSC-BTB) [13]-[14] and VSC transmission [5]. In addition to these referenced and other applications, there are several recently completed STATCOMs in the US., in the states of Vermont [15]-[16], California and Texas . In addition, there are new1y planned STATCOMs in Connecticut [9] and Texas, as well as a small STATCOM (D-VAR) planned

Manuscript received January 16, 2012; revised March 28, 2012.

Sobuj Kumar Ray is with Faculty of Dept. EEE, IUBAT (e-mail: sobuj_kumar_ray@yahoo.com).

Pejush Chandra Sarker is with Faculty of Dept. EEE, UAP (e-mail: pejush01@yahoo.com).

Munshi Sabbir Ahsan is with Grameen Phone Ltd. (e-mail: saikat_kazoli@yahoo.com).

Mr. M. M. Israfil Shahin Seddiqe is with RUET. (e-mail: mmisrafil@gmail.com). for BC Hydro [10] and several other locations. Other installations of power electronic equipment includes Distributed Superconducting Magnetic Energy Storage units (D-SMES)[11]. These aforementioned transmission system installations are in addition to the earlier generation of power electronics systems that utilize line-commutated thyristor technology for Static Var Compensators (SVC) and Thyristor Controlled Series Compensators (TCSC) .

The congestion management in deregulated power system and to utilize the FACTS devices in that application studies in [17]. It uses the static modeling of TCSC and the static modeling of UPFC, especially for UPFC modeling, it uses the injection model of UPFC. The fitness function is termed by the loading of the transmission lines in exponential mathematical formula. According to the proposed fitness function, to reduce more significantly the loading of the lines, we want to install more than FACTS devices, which may give reflection for the cost of the power in the system. The simulations are applied on IEEE 30-bus system. A method for optimal location of UPFC in power systems to increase the loadability using genetic algorithm is presented in [18]-[19]. The model for UPFC, which is used in the papers, is the injection model of UPFC.

PID controller consists the $\mathrm{P}$ control action, I control action and $\mathrm{D}$ control action. The $\mathrm{P}$ action is the control action that is proportional to the actuating error signal, which is the difference between the input and the feedback signal. The I action is the control action which is proportional to the integral of the actuating error signal. Finally the D action is the control action which is proportional to the derivative of the actuating error signal. With the integration of all the three actions, the continuous PID can be realized. This type of controller is widely used in industries all over the world. In fact a lot of research, studies and application have been discovered in the recent years.

\section{Mathematical Model OF THE POWER SySTEM WITH AND WITHOUT FACTS}

\section{A. Modeling Simple Single Machine Infinite Bus}

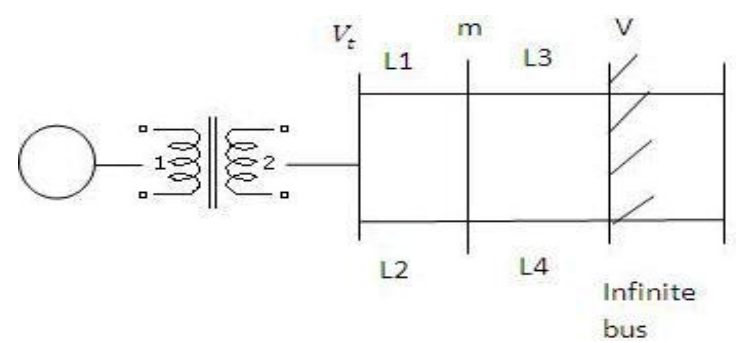

Fig. 1. Single machine infinite bus system

Consider a simple Single Machine Infinite Bus (SMIB) 
system shown in Fig. 1. Without any FACTS device. The system consists of a single machine connected to an infinite bus through two identical transmission lines.

The equivalent circuit of the system is shown in Fig.2. where $\mathrm{X} 1$ represent the equivalent reactance between machine internal bus and the impedance bus X1. and X2 represent the equivalent reactance between the bus $\mathrm{m}$ and the infinite bus.

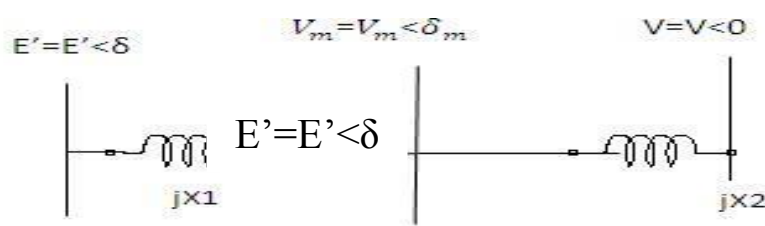

Fig. 2. Equivalent circuit of single machine infinite bus system

The magnitude of the machine internal voltage and the infinite bus voltage is represented by $E^{\prime}$ and $V$, respectively. The dynamics of the machine in the classical model can be represented by the following equations.

$$
\begin{gathered}
\frac{d \delta}{d t}=\omega \\
\frac{d \omega}{d t}=\frac{1}{M}\left(P_{m}-P_{e}-D_{\omega}\right)
\end{gathered}
$$

Here $\delta, \omega, \mathrm{M}, \mathrm{P}_{\mathrm{m}}$ and $\mathrm{D}$ are the rotor angle deviation, rotor speed deviation, moment of inertia, input mechanical power and damping coefficient, respectively of the machine. The electrical output power $\mathrm{P}_{\mathrm{e}}$ of the machine in Fig. 2. can be written as

$$
P_{e}=P_{\max } \operatorname{Sin} \delta
$$

where

$$
P_{\max }=\frac{E^{\prime}}{X_{1}+X_{2}}
$$

\section{B. Modeling of STATCOM}

STATCOM is a shunt connected reactive-power compensation device that is capable of generating and / or absorbing reactive power and in which the output can be varied to control the specific parameters of an electric power system. It is in general a solid-state switching converter capable of generating or absorbing independently controllable reactive power at its output terminal.

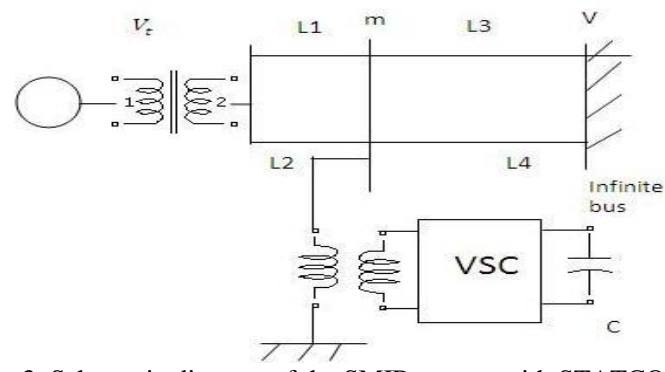

Fig. 3. Schematic diagram of the SMIB system with STATCOM.

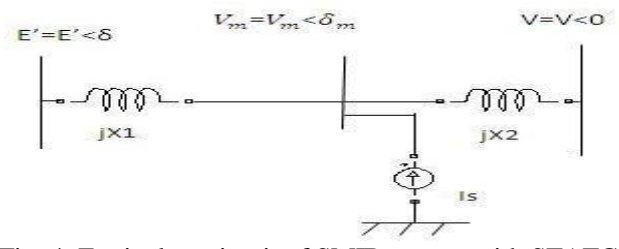

Fig. 4. Equivalent circuit of SMIB system with STATCOM.
The STATCOM is placed in the bus $\mathrm{m}$ and is represented by a shunt reactive current source $I_{s}$ as show in Fig. 3. and Fig. 4.

where

$$
I_{S}=I_{S} e^{j\left(\delta_{m} \pm \pi / 2\right)}
$$

Here

$$
\delta_{m}=\tan ^{-1}\left(\frac{E X_{2} \sin \delta}{V X_{1}+E^{\prime} X_{2} \cos \delta}\right)
$$

With the STATCOM the output power $\mathrm{P}_{\mathrm{e}}$ of the machine can be written as

$$
P_{e}=P_{\max } \sin \delta+f_{1}(\delta) I_{S}
$$

where

$$
f_{1}(\delta)=\frac{E^{\prime} X_{2}}{X_{1}+X_{2}} \sin \left(\delta-\delta_{m}\right)
$$

Is positive when $\delta$ oscillates in between zero and $\pi$. Equation of $\mathrm{P}_{\mathrm{m}}$ suggests that it can be modulated by modulating the shunt reactive current $\mathrm{I}_{\mathrm{s}}$.

For enhancement of power system damping the shunt reactive current can be modulated in propagation to the rotor speed deviation $\omega$. With this control signal $\mathrm{I}_{\mathrm{s}}$ can be expressed as

$I_{S}=K_{1} \omega, \quad-I_{S}^{\max } \leq I_{S} \leq I_{S}^{\max }$ Where, $\mathrm{K}_{1}$ is a positive constant.

\section{Modeling of SSSC}

SSSC is a series connected synchronous voltage source that can vary the effective impedance of a transmission line by injecting a voltage containing an appropriate phase angle in relation to the line current. If the injected voltage is in phase with the line current, then the voltage would exchange the real power. On the other hand if the injected voltage injected in quadrature with line current, then reactive power would be exchanged.

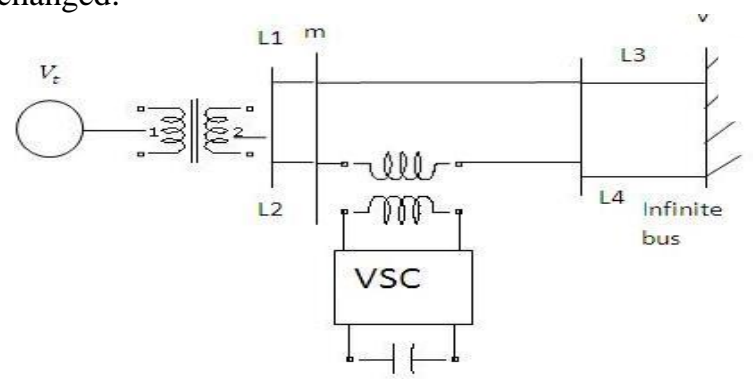

Fig. 5. Schematic diagram of the SMIB system with SSSC.

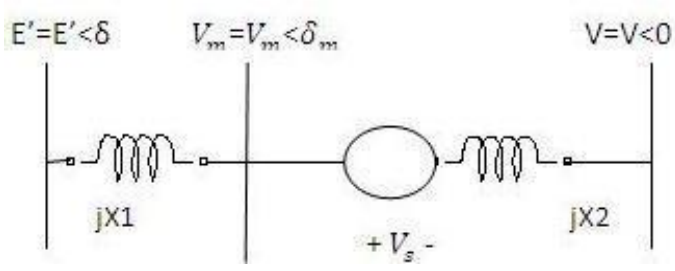

Fig. 6. Equivalent circuit of SMIB system with SSSC

Consider that a SSSC is placed near bus $m$ in the system as shown in Fig. 5. and Fig. 6. The SSSC is represented by a series voltage source

The series voltage injected by the SSSC is given by

$$
V_{S}=V_{S} e^{j(\theta \pm \pi / 2)}
$$


where $\theta$ is the angle of the line current and is given by

$$
\theta=\tan ^{-}\left(\frac{V-E^{\prime} \cos \delta}{E^{\prime} \sin \delta}\right)
$$

With the SSSC the machine power $\mathrm{P}_{\mathrm{e}}$ can written as

$$
P_{e}=P_{\max } \sin \delta+f_{2}(\delta) V_{S}
$$

where

$$
f_{2}(\delta)=\left(\frac{P_{\max } \sin \delta}{E^{\prime 2}-2 E^{\prime} V \cos \delta}\right)
$$

$\mathrm{f}_{2}(\delta)$ is positive when $\delta$ oscillates in between 0 and $\pi$.

$\mathrm{P}_{\mathrm{e}}$ can be modulated by properly controlling the value of $\mathrm{V}_{\mathrm{S}}$.

$\mathrm{V}_{\mathrm{S}}$ can be expressed as

$$
V_{S}=K_{2} \omega, \quad-V_{S}^{\max } \leq V_{S} \leq V_{S}^{\max }
$$

$\mathrm{K}_{2}$ is a positive constant.

\section{Modeling of UPFC}

Unified Power Flow Controller is the most versatile FACTS controller developed so far, with all encompassing capabilities of voltage regulation, series compensation and phase shifting. It can independently control both the real and reactive power flows in a transmission line. It comprises two voltage sourced converters coupled through a common DC terminal. One Voltage Source Converter (VSC) is connected in shunt with the line through a coupling transformer and the other VSC inserted in series with the transmission line through an interface transformer.

The series converter exchanges both real and reactive power within the transmission line. The shunt connected converter 1 is used mainly to supply the real power demand of converter 2, which derives from the transmission line itself. The shunt converter maintains constant voltage of the DC bus. Thus the net real power drawn from the AC system equal to the losses of two converters and their coupling transformers

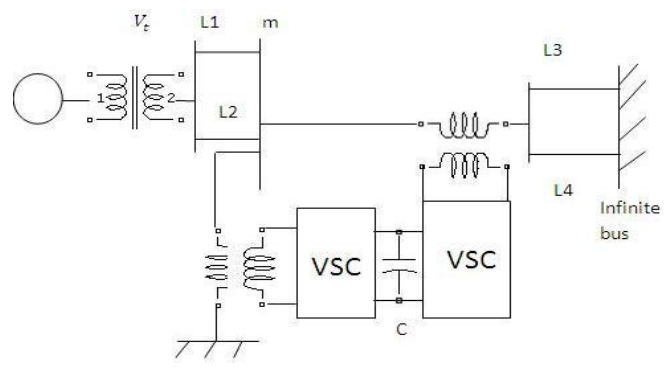

Fig. 7. Schematic diagram of the SMIB system with UPFC.

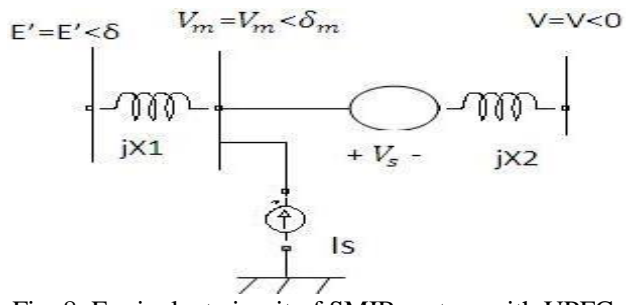

Fig. 8. Equivalent circuit of SMIB system with UPFC.

The equivalent circuit of UPFC can be represented as a shunt current source and a variable voltage source as formulated by Navabi and Iravani (1996). The single line diagram and equivalent circuit are given in Fig. 7. and Fig. 8.

The mathematical expression of Static Synchronous Series Compensator (SSSC) and Static Compensator (STATCOM) will be combined to show the damping improvement of the system with UPFC. With the UPFC the machine power $\mathrm{P}_{\mathrm{e}}$ can written as

$$
P_{e}=P_{\max } \sin \delta+f_{1}(\delta) I_{S}+f_{2}(\delta) V_{S}
$$

where, the value of $\mathrm{P}_{\max } \delta, \mathrm{f}_{1}(\delta)$ and $\mathrm{f}_{2}(\delta)$ are given in

\section{Simulation AND RESUlT}

Simulation of STACOM, SSSC and UPFC by using Matlab simulink is below.
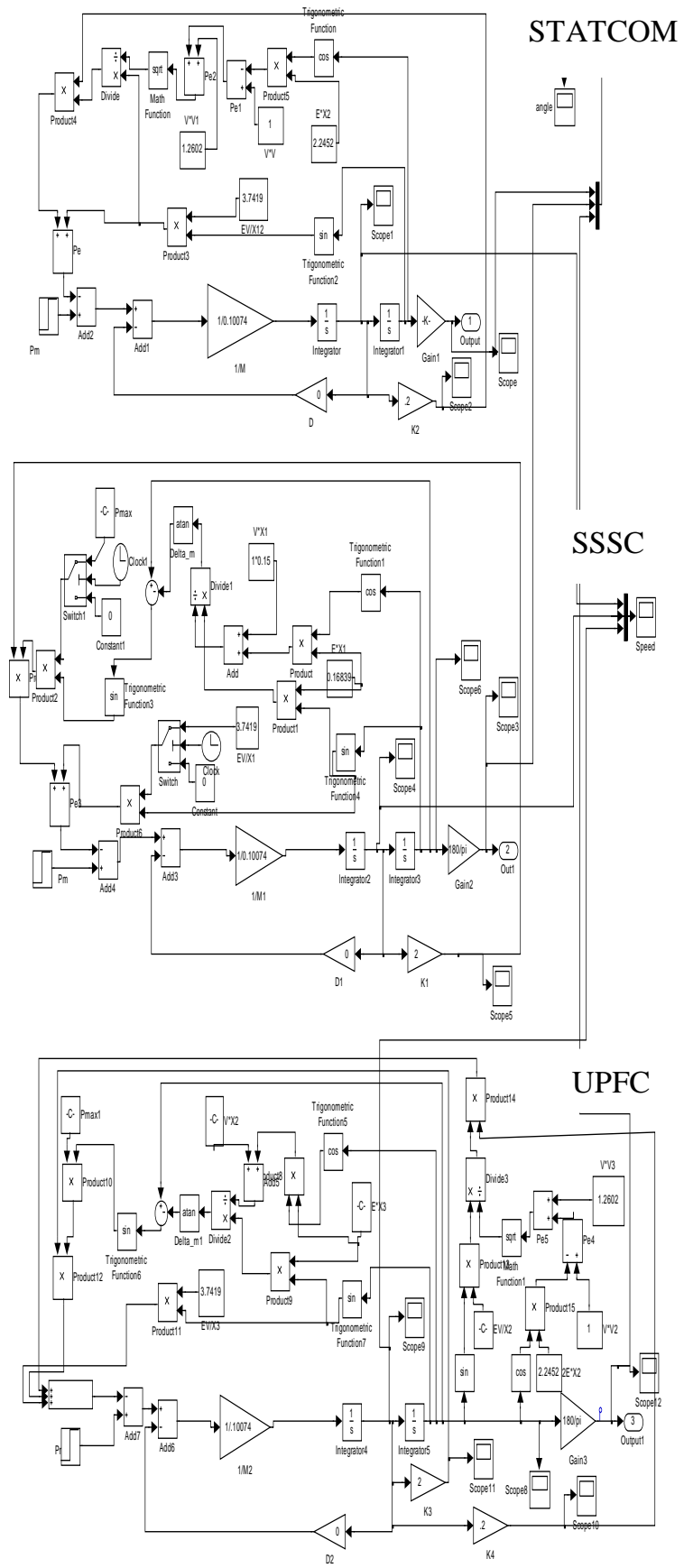

Fig. 9. Single Machine Infinite Bus Power System with STATCOM, SSSC, UPFC 
Fig. 10 and 11 represent rotor angle and speed deviation respectively due to step change in the Turbine Mechanical Input, $\Delta \mathrm{pm}=0.1 \mathrm{p} . \mathrm{u}$.

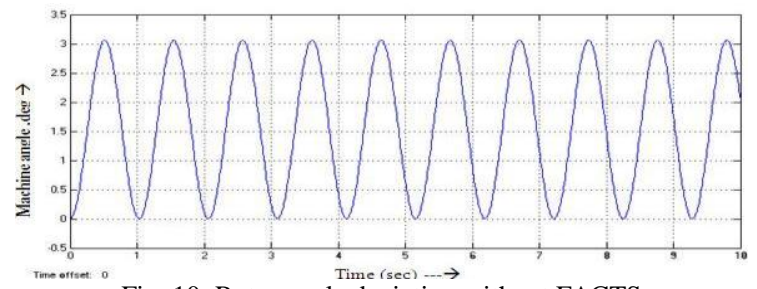

Fig. 10. Rotor angle deviation without FACTS

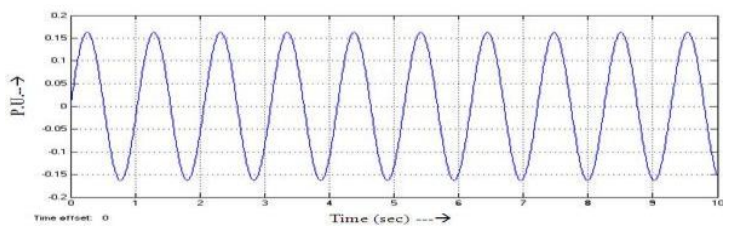

Fig. 11. Rotor speed deviation without FACTS

Fig. 12 and 13 represent injected current and voltage by the STATCOM and SSSC respectively due to step change in the Turbine Mechanical Input, $\Delta \mathrm{pm}=0.1 \mathrm{p}$.u.

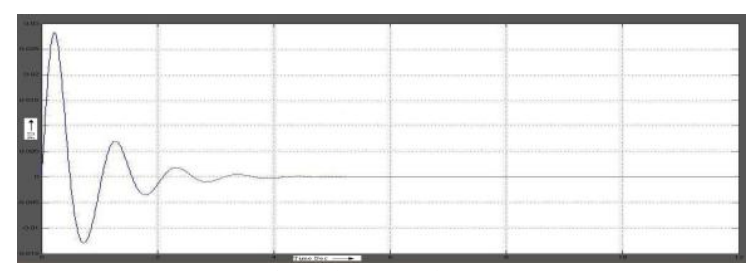

Fig. 12. Injected current by STATCOM

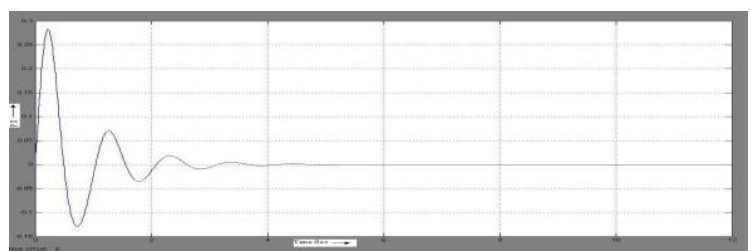

Fig. 13. Injected voltage by SSSC

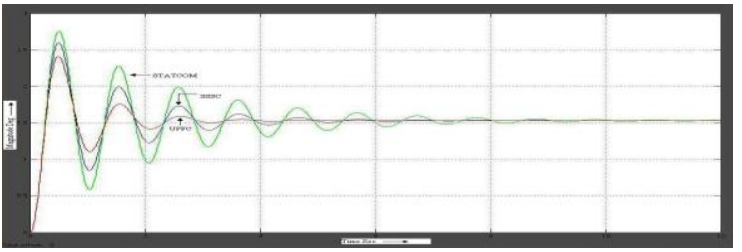

Fig. 14. Rotor angle deviation with STACOM, SSSC and UPFC

TABLE I: Rotor ANGLE DEVIATION
\begin{tabular}{|c|c|c|}
\hline Device & Maximum overshoot & Settling time \\
\hline STSTCOM & 2.75 & 10 \\
\hline SSSC & 2.6 & 6 \\
\hline UPFC & 2.4 & 4 \\
\hline
\end{tabular}

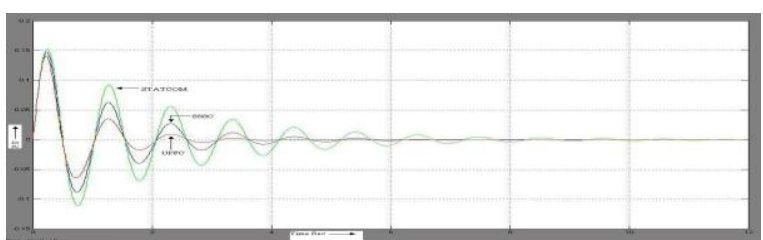

Fig. 15. Rotor speed deviation with STACOM, SSSC and UPFC

TABLE II: Rotor speed deviation

\begin{tabular}{|c|c|c|}
\hline \multicolumn{3}{|c|}{ TABLE II: Rotor speed deviation } \\
\hline Device & Maximum overshoot & Settling time \\
\hline STSTCOM & 0.151 & 10 \\
\hline SSSC & 0.149 & 6 \\
\hline
\end{tabular}

\begin{tabular}{|c|c|c|} 
UPFC & 0.148 & 4 \\
\hline
\end{tabular} Fig. 14 and 15 represent rotor angle deviation and speed deviation respectively for STATCOM, SSSC and UPFC. From these Fig. and table I and II it's clear that damping of oscillation is improving and mitigating to large amount. Simulation of STATCOM, SSSC, UPFC with PID controller.
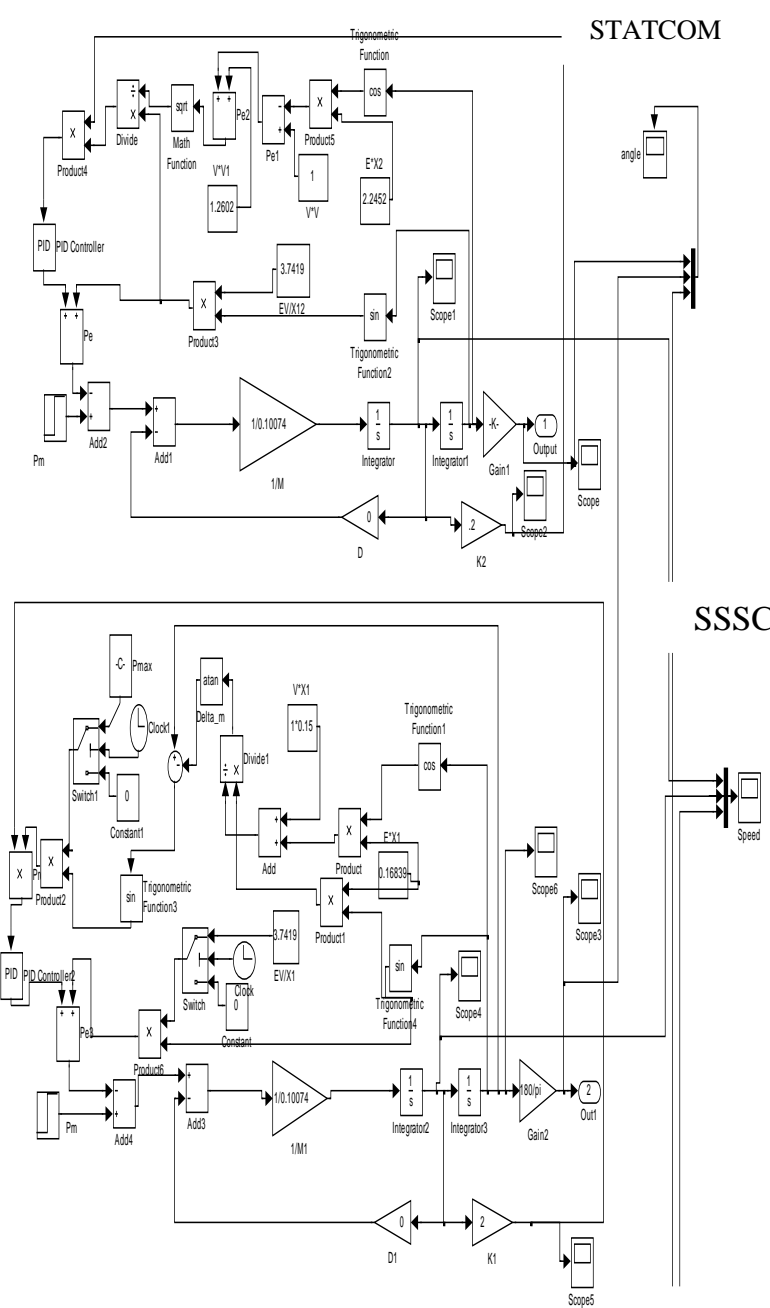

UPFC

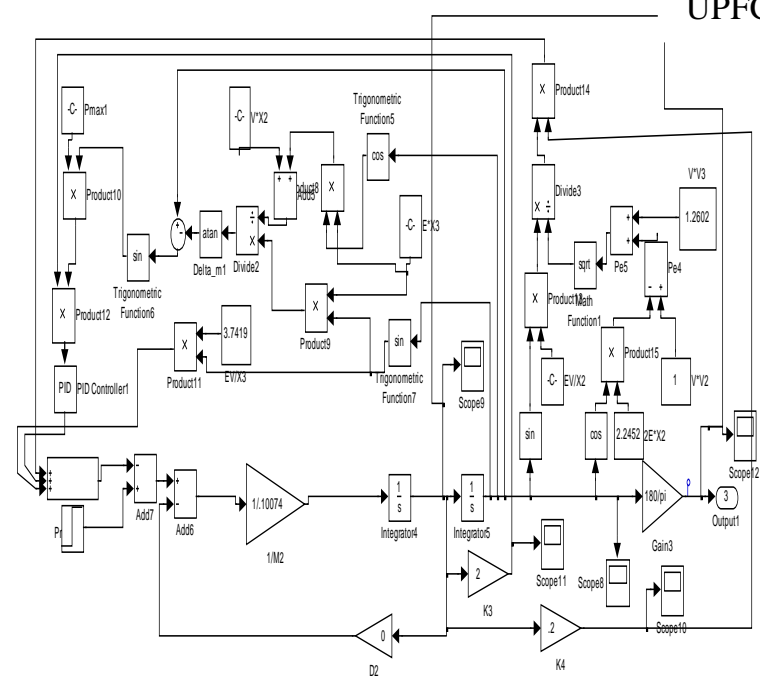

Fig. 16. Single machine infinite bus power system with STATCOM, SSSC, UPFC and PID

TABLE III: GAIN OF PID CONTROLLER

\begin{tabular}{|l|l|l|}
\hline$K_{\mathrm{p}}$ & $\mathrm{K}_{\mathrm{I}}$ & $\mathrm{K}_{\mathrm{d}}$ \\
\hline
\end{tabular}




\begin{tabular}{|l|l|l|}
\hline 10 & 0.005 & 0.1 \\
\hline
\end{tabular}

Fig. 17 and 18 represent injected current and voltage respectively when PID controller is incorporated with STACOM and SSSC.

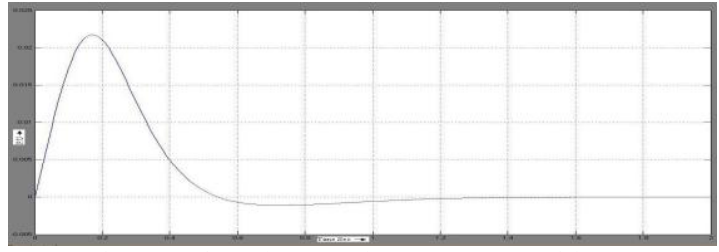

Fig. 17. Injected current by STATCOM with PID

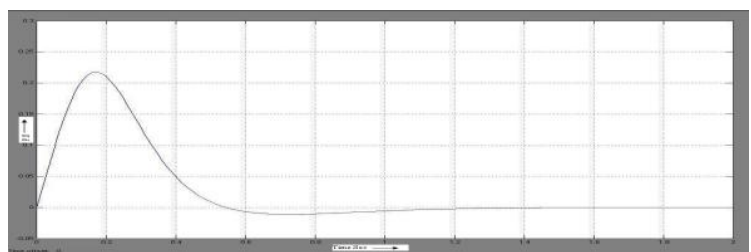

Fig. 18. Injected voltage by SSSC with PID

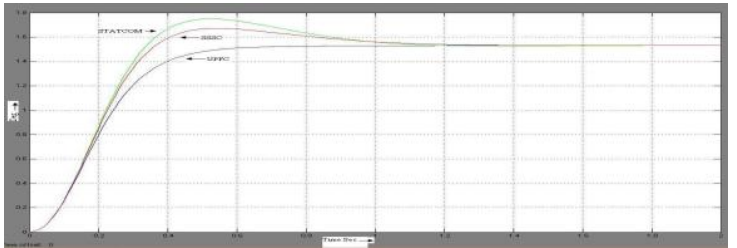

Fig. 19. Rotor angle deviation with PID controller

TBBLE IV: ROTOR ANGLE WITH PID CONTROLLER DEVIATION

\begin{tabular}{|c|c|c|}
\hline Device & Maximum overshoot & Settling time \\
\hline STSTCOM & 1.76 & 1.2 \\
\hline SSSC & 1.63 & 1.1 \\
\hline UPFC & 1.5 & 0.8 \\
\hline
\end{tabular}

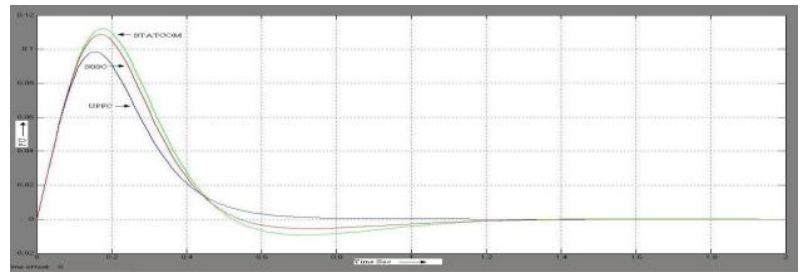

Fig. 20. Rotor speed deviation of STACOM, SSSC, UPFC with PID controller

TABLE V: ROTOR SPEED WITH PID CONTROLLER

\begin{tabular}{|c|c|c|}
\hline Device & Maximum overshoot & Settling time \\
\hline STSTCOM & 0.16 & 10 \\
\hline SSSC & 0.14 & 6 \\
\hline UPFC & 0.09 & 4 \\
\hline
\end{tabular}

From Fig. 19 and 20 and table IV and V it's clear that damping of oscilation is improving and mitigating tremendously.

Now, Consider three phase faults occurred at bus $\mathrm{M}$ as shown in Fig. 7. then rotor angle deviation and speed deviation can be represented by Fig. 21 and 22 respectively.

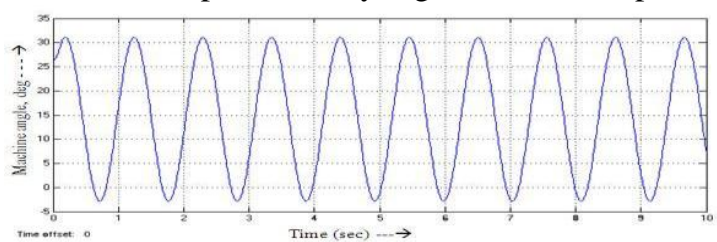

Fig. 21. Rotor angle deviation without FACTS

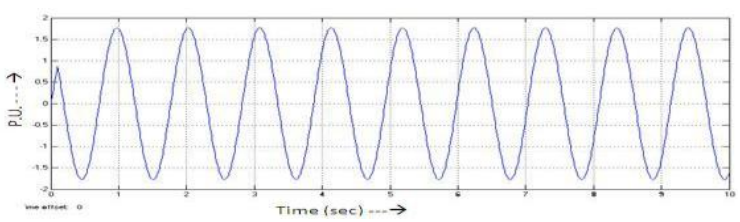

Fig. 22. Rotor speed deviation without FACTS

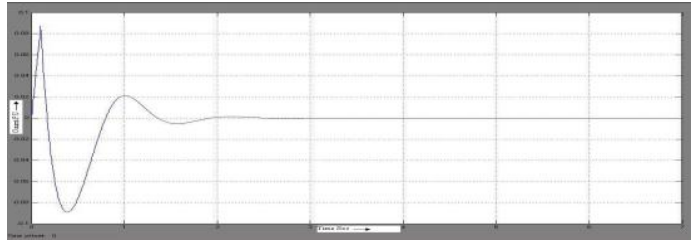

Fig. 23. Injected current by STATCOM

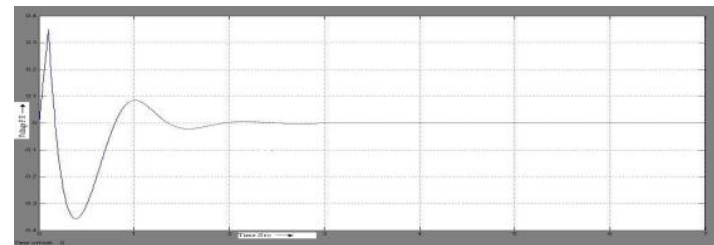

Fig. 24. Injected voltage by SSSC

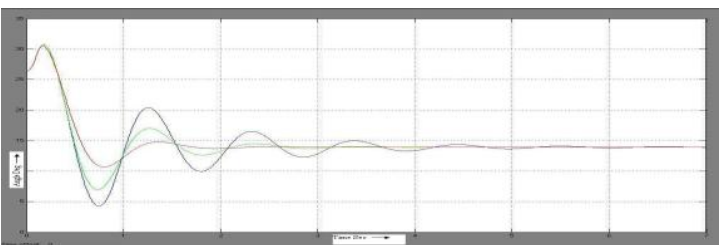

Fig. 25. Rotor angle deviation with STATCOM, SSSC, UPFC

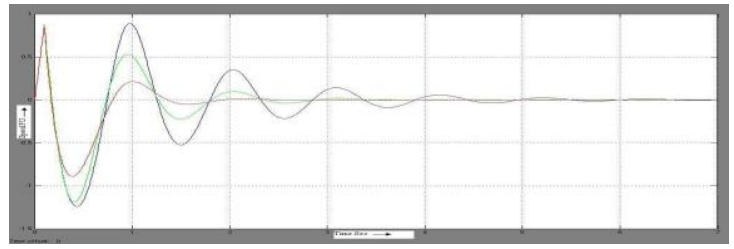

Fig. 26. Rotor angle deviation with STATCOM, SSSC, UPFC

Now we may incorporate PID Controller with STATCOM, SSSC and UPFC under fault condition at bus M.

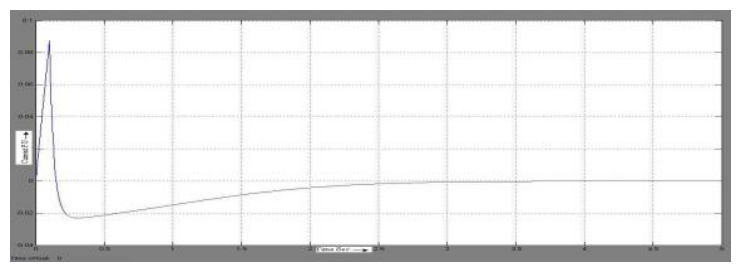

Fig. 27. Injected current by STATCOM with PID

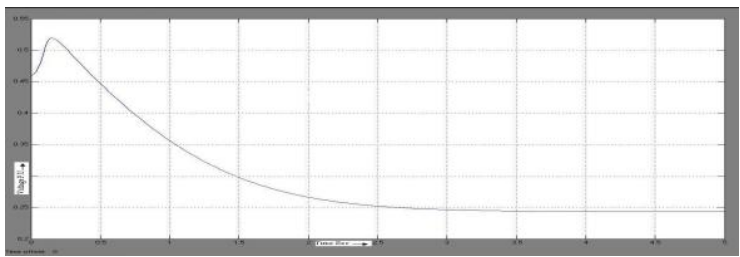

Fig. 28. Injected voltage by SSSC with PID

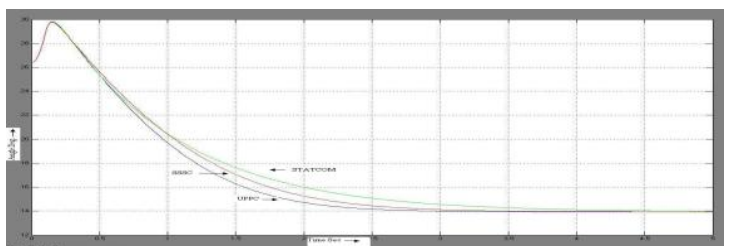

Fig. 29. Rotor angle deviation with STATCOM, SSSC, UPFC and PID 


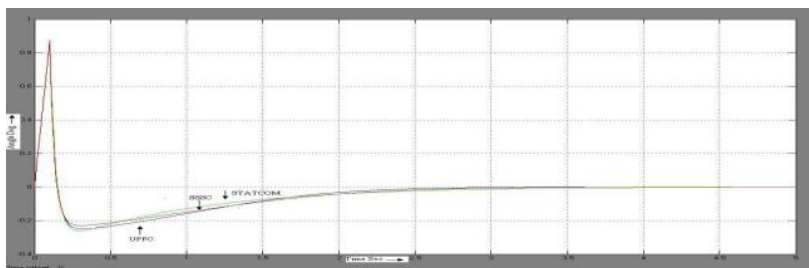

Fig. 30. Rotor speed deviation with STATCOM, SSSC, UPFC and PID

For large disturbance the FACT devices and PID controller serve for improving damping and mitigating oscillation which we may investigate from Fig. 23 to Fig 30.

\section{CONCLUSION}

This paper provides a comprehensive summary of electromechanical damping oscillation and transient response for practical application. Simulation results depict that for small step change to the turbine mechanical input creates large change to the rotor angle deviation and speed deviation. But after applying STATCOM, SSSC and UPFC the damping of oscillation is reduced to considerable part. Again, after incorporating PID controller with STATCOM, SSSC and UPFC the damping of oscillation is reduced to tremendous portion. Hence, the results give useful information on the transient rating of FACTS with PID controllers for small disturbance/large disturbance stability enhancement.

\section{REFERENCES}

[1] Jiang. X, Chow J. H, Edris A, and Fardanesh B, "Transfer path stability enhancement by voltage-sourced converter-based FACTS controllers," IEEE Trans. Power Deliv, vol. 25, pp. 1019-1025, 2010.

[2] Zarghami M, Crow ML, Sarangapani J, Liu Y and Atcitty S "Anovel approach to inter-area oscillations damping by Unified Power Flow Controllers utilizing ultra-capacitors," IEEE Transactions on Power Systems, vol. 25. no. 1 , pp. $404-412,2010$.

[3] Jiang. X, Chow J. H, Edris A, and Fardanesh B "Transfer path stability enhancement by voltage-sourced converter-based FACTS controllers," IEEE Transactions on Power Delivery. Vol. 25, no. 2, pp. 1019 $1025,2010$.

[4] Guo. J, Crow M. L and Sarangapani. J, "An improved UPFC control for oscillation damping" IEEE Transactions on Power Systems. Vol. 25, no. 1 , pp. $288-296,2010$.

[5] S. Mori, K. Matsuno, T. Hasegawa, S. Ohnishi, M. Takeda, M. Seto, S. Murakami, and F. Ishiguro, "Development of a Large Static Var Generator Using Self-Commutated Inverters for Improving Power System Stability," IEEE Transactions on Power Systems, Vol. 8, No. 1, pp.371-377, February, 1993,

[6] M. Hirakawa, H. Somiya, Y. Mino, K. Baba, S. Murakami, and Y. Watanabe, "Application of Self-Commutated Inverters to Substation Reactive Power Control," CIGRE Paper 23-205, Paris Session, 1996.

[7] C. Schauder, M. Gernhardt, E. Stacey, T. Lemak, L. Gyugyi, T. W. Cease, Edris, and M. Wilhelm, "TVA STATCOM Project: Design, Installation, and Commissioning," CIGRE Paper 14-106, Paris General Session, 1996.

[8] C. Schauder, "STATCOM for Compensation of Large Electric Arc Furnace Installations," Proc. of the IEEE PES Summer Power Meeting, Edmonton, Alberta, pp. 1109-1112 July 1999.

[9] D. J. Hanson, C. Horwill, B. D. Gemmell, and D. R. Monkhouse, "A STATCOM-Based Relocatable SVC Project in the UK for National Grid," Proc. of the IEEE PES Winter Power Meeting, New York, January 2002.

[10] C. Schauder, E. Stacey, M. Lund, L. Gyugyi, L. Kovalsky, A. Keri, Mehraban, and A. Edris, "AEP UPFC Project: Installation, Commissioning and Operation of The \pm 160 MVA STATCOM (Phase I)," IEEE Transactions on Power Delivery Vol. 13, No. 4, pp. 1530-1535, October 1998.

[11] B. A. Renz, A. J. F. Keri, A.S. Mehraban, J. P. Kessinger, C. D. Schauder, L. Gyugyi, L. J. Kovalsky, and A. A. Edris, "World's First
Unified Power Flow Controller on the AEP System," CIGRE Paper 14-107, Paris Session, 1998.

[12] B. Fardanesh, M. Henderson, B. Shperling, S. Zelingher, L. Gyugyi, C. Schauder, B. Lam, J. Mountford, R. Adapa, and A. Edris, "Convertible Static Compensator Application to the New York Transmission System," CIGR Paper 14-103, Paris Session, 1998.

[13] H. Suzuki, M. Takeda, and G. Reed, "Application of Voltage Source Converter Technology to a Back-to-Back DC Link," Proc. of the IEEE PES Summer Power Meeting, Edmonton, Alberta, July 1999.

[14] T. Larsson A. Edris, D. Kidd, and F. Aboytes, "Eagle Pass Back-to-Back Tie: a Dual Purpose Application of Voltage Source Converter Technology," Proc. of the 2001 IEEE PES Summer Power Meeting, Vancouver, BC, July 2001

[15] G. Reed, J. Paserba, T. Croasdaile, M. Takeda, Y. Hamasaki, T. Aritsuka, N. Morishima, S. Jochi, I. Iyoda, M. Nambu, N. Toki, L. Thomas, G. Smith, D. LaForest, W. Allard, and D. Haas, "The VELCO STATCOM-Based Transmission System Project," Proc. of the 2001 IEEE PES Winter Power Meeting, Columbus, OH, January/February 2001.

[16] G. Reed, J. Paserba, T. Croasdaile, M. Takeda, N. Morishima, Y Hamasaki, L. Thomas, and W. Allard, "STATCOM Application at VELCO Essex Substation," Proc. of the IEEE PES T\&D Conference and Exposition, Atlanta, Georgia, October/November 2001.

[17] K. R. Saidi, N. P. Padhy, and R. N. Patel, "Congestion Management in Deregulated Power System using FACTS Devices," International IEEE Power India Conference, India, 10-12, April 2006.

[18] A. Kazemi, D. Arabkhabori, M. Yari, and J. Aghaei, "Optimal Location of UPFC In Power Systems for Increasing Loadability By Genetic Algorithm," Universities Power Engineering Conference, UPEC '06, UK, Vol. 2, pp. 774- 779, Sept. 2006.

[19] D. Arabkhabori, A. Kazemi, M. Yari, and J. Aghaei, "Optimal Placement of UPFC In Power Systems using Genetic Algorithm," IEEE International Conference on Industrial Technology (ICIT), India, pp. 1694 - 1699, 18-21 Dec. 2006.

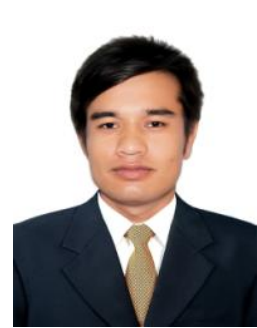

Sobuj Kumar Ray received Bachelor degree in Electrical and Electronic Engineering from the Rajshahi University of Engineering and Technology (RUET), Rajshahi, Bangladesh. Now he is a faculty in the department of Electrical and Electronic Engineering, Internal University of Business Agriculture and Technology, Dhaka, Bangladesh. He is highly enthusiastic in research on control and power system.

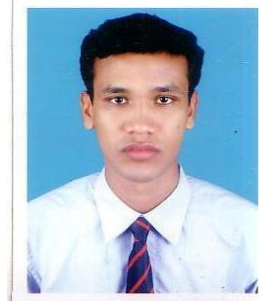

Mr. Pejush Chandra Sarker completed graduation in Electrical and Electronic Engineering from Rajshahi University of Engineering and Technology (RUET), Rajshahi, Bangladesh in April 2010. Now he works as a lecturer in the department of Electrical and Electronic Engineering, the University of Asia Pacific, Bangladesh (www.uap-bd.edu). The major fields of study of Mr. Sarker comprise power system, control system, Communication system etc.

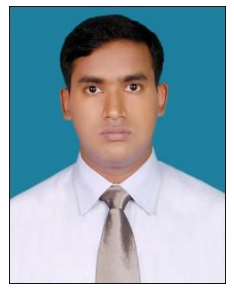

Munshi Sabbir Ahsan received his Bachelor degree in Electrical and Electronic Engineering from the Rajshahi University of Engineering and Technology (RUET), Rajshahi, Bangladesh in April 2010. Now he is in Grameen Phone Ltd. (www.grameenphone.com) as a System Engineer in

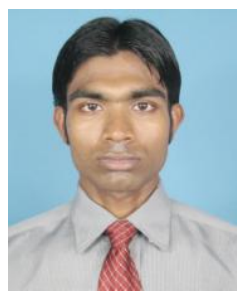

M. M. Israfil Shahin Seddiqe was born in 1988. Mr. Israfil received his Bachelor degree in Electrical and Electronic Engineering from Rajshahi University of Engineering and Technology (RUET), Rajshahi,Bnagladeshin April 2010. The major fields of study is control system. 